\title{
Arqueoturismo:
}

\section{repensando o turismo nas Itacoatiaras do Ingá - PB}

Archeotourism: rethinking tourism in the Itacoatiaras do Ingá, PB, Brazil Arqueoturismo: repensando el turismo en las Itacoatiaras do Ingá, PB, Brazil

http://dx.doi.org/10.18472/cvt.18n2.2018.1311

Luciana Arruda Falcão < lucafalcao@hotmail.com >

Universidade Federal da Paraíba (UFPB), João Pessoa, PB, Brasil

Amada Gama Tavares < amada.tavares@hotmail.com >

Universidade Federal da Paraíba (UFPB), João Pessoa, PB, Brasil

Ilana Kiyotani <ilana.kiyotani@gmail.com〉

Universidade Federal da Paraíba (UFPB), João Pessoa, PB, Brasil

CRONOLOGIA DO PROCESSO EDITORIAL

Recebimento do artigo: 07-jul-2016

Aceite: 02-mar-2018

FORMATO PARA CITAÇÃO DESTE ARTIGO

FALCÃO, L. A.; TAVARES, A. G.; KIYOTANI, I. Arqueoturismo: repensando o turismo nas

Itacoatiaras do Ingá - PB. Caderno Virtual de Turismo. Rio de Janeiro, v. 18, n. 2, p. 104-120, ago. 2018.

REALIZAÇÃO

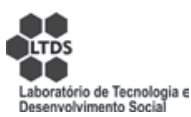

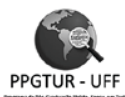

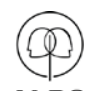

APOIO INSTITUCIONAL

EDIÇÃO

PATROCÍNIO

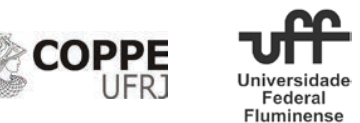




\section{RESUMO}

As facilidades de acesso a sítios arqueológicos e o interesse natural do ser humano em conhecer mais sobre seus ancestrais remotos abriram caminhos para o fortalecimento das sinergias entre arqueologia e turismo. Tal relação gerou o que se chama de arqueoturismo, que consiste em viagens motivadas pelo desejo de visitar locais onde há vestígios materiais do processo evolutivo humano. Considerando essa possibilidade para o Brasil e percebendo suas dificuldades em fazer funcionar esse segmento, neste trabalho busca-se verificar as atuais condições de visitação turística de um dos seus sítios arqueológicos: as Itacoatiaras do Ingá, na Paraíba. Para isso, usou-se pesquisa bibliográfica e documental, somando a pesquisa de campo - visita in loco e entrevista com o gestor municipal. A análise dos dados possibilitou a conclusão de que os recursos de Ingá são subaproveitados, sendo necessárias diversas medidas para sua melhor integração à atividade turística.

Palavras-chave: Turismo Cultural. Arqueoturismo. Sítio Arqueológico Itacoatiaras do Ingá/PB.

\section{ABSTRACT}

The access facilities to archaeological sites and the man's natural interest in knowing more about their ancestors have paved the way for the strengthening of synergies between archeology and tourism. This relationship led to what is called archeotourism, consisting of travel motivated by the desire to visit places where there are material remains of the human evolutionary process. Considering this possibility for Brazil and realizing its difficulty to operate this segment, this study aims to check the current tourist visitation conditions of one of its archaeological sites: the Itacoatiaras do Ingá, Paraíba. For this, it was used bibliographical and documentary research, and field research - on-site visit and interview with the municipal manager. Data analysis enabled the conclusion that Ingá resources are underutilized, requiring several steps to better integrate the tourist activity.

Keywords: Cultural tourism. Archeotourism. Archeological Site Itacoatiaras do Ingá, Paraíba, Brazil.

\section{RESUMEN}

Las facilidades de acceso a los sitios arqueológicos y el interés natural del hombre en saber más acerca de sus antepasados abrieron camino para el fortalecimiento de las sinergias entre la arqueología y el turismo. Esta relación dio lugar a lo que se llama arqueoturismo, que consiste en los viajes motivados por el deseo de visitar lugares donde hay evidencia material del proceso evolutivo humano. Teniendo en cuenta esta posibilidad para el Brasil y al darse cuenta de sus dificultades para desarrollar ese segmento, el presente trabajo pretende verificar las actuales condiciones de visita turística de uno de sus sitios arqueológicos: el Itacoatiaras do Ingá, en Paraíba. Para ello, se utilizó la investigación bibliográfica y documental, en adición, la investigación de campo - visita in loco y entrevista con el gestor municipal. El análisis de los datos posibilitó la conclusión de que son subutilizados los recursos de Ingá, lo que requiere varios pasos para integrarle mejor a la actividad turística.

Palavras clave: Turismo Cultural. Arqueoturismo. Sitio arqueológico Itacoatiaras do Ingá, Paraíba, Brasil. 


\section{INTRODUÇÃO}

Por contarem a história do ser humano, além de conter beleza visual, o patrimônio arqueológico atrai o olhar das pessoas. Avanços em pesquisas têm facilitado o acesso aos locais com artes rupestres ou ruínas de antigas civilizações, por exemplo, viabilizando uma sinergia entre a arqueologia e o turismo. A atividade tem sido denominada arqueoturismo, consistindo também em um eixo temático do turismo cultural (TRESSERRAS, 2004; MANZATO, 2005; ALEIXO, 2010).

Sítios arqueológicos são fortes atrativos turísticos em países europeus, como Itália e Grécia, e americanos, como México e Peru, entre outros. No Brasil, tendo em vista os vestígios deixados por povos antigos em vários pontos do território nacional, essa relação também é possível. O arqueoturismo seria, portanto, uma alternativa para diversificação da oferta, aumento da competitividade e fortalecimento da atividade em Estados que enfrentam dificuldades nesse setor.

O estado brasileiro da Paraíba conta com o Sítio Arqueológico das Itacoatiaras do Ingá, referência internacional de arqueologia e o primeiro Monumento Arqueológico tombado pelo Iphan já em 1944. No entanto, passados 74 anos, o sítio não tem recebido os devidos cuidados, tampouco apresentado êxito na atração de arqueoturistas, sendo visível seu pouco aproveitamento turístico. Dificuldades de reconhecimento, manutenção e preservação muitas vezes ultrapassam os recursos e a motivação para aproveitar o potencial.

É de se questionar, portanto, qual o contexto de (falta de) reconhecimento e uso de tal patrimônio pelo turismo. Esta pesquisa objetiva verificar as condições de visitação do atrativo paraibano Sítio Arqueológico das Itacoatiaras do Ingá, de forma a identificar medidas possíveis e viáveis a sua integração à atividade turística.

A pesquisa qualitativa usou os seguintes procedimentos metodológicos: pesquisa bibliográfica, embasando a temática e apresentando casos do segmento; pesquisa documental, conhecendo o andamento de estudos e processos de qualificação e revitalização da área; observação sistemática, em uma primeira visita ao local, em setembro de 2013, e entrevista semiestruturada, em junho de 2014, com o secretário municipal de Turismo. O recorte temporal foi de 2005 a 2014, a fim de ser possível acompanhar as ações de gestões distintas.

\section{Arqueoturismo: fazendo do patrimônio atrativo turístico}

Os avanços nas técnicas e nas pesquisas arqueológicas têm facilitado a acessibilidade a significativa parte dos sítios arqueológicos no mundo. Isso proporciona impactos de fortalecimento em diversos âmbitos: científico, social, cultural, educativo e turístico. O turismo é incluso na lista devido ao que se tem denominado de arqueoturismo, segmento pouco cultivado e divulgado, mas que tem seu valor. Essa sinergia tem sido alvo de muitos projetos (ABADIA; RAMBELLI, 2013).

Também chamado de turismo arqueológico, consiste em viagens motivadas pelo desejo de conhecer aspectos de culturas passadas, com a intenção de visitar locais onde há vestígios materiais do processo evolutivo humano, tais como sítios arqueológicos, seja pré-históricos ou históricos, seja terrestres ou subaquáticos (NÓBREGA; ARAÚJO, 2015; ALEIXO, 2010; WIDMER, 2009; MANZATO, 2005). 
"El arqueoturismo o turismo arqueológico es una modalidad bajo la que se presentan propuestas y productos culturales y turísticos en los que la arqueología es el ingrediente principal" (TRESSERRAS, 2004, p. 2). Claramente, o elemento primordial ao desenvolvimento do arqueoturismo é o patrimônio arqueológico, que faz parte do Patrimônio Cultural ${ }^{1}$. Por sua relação com a cultura, refere-se a um segmento desmembrado a partir da demanda gerada pelo turismo cultural.

Considerando a fragilidade do patrimônio cultural arqueológico, órgãos se encarregam por sua regulamentação, conceituação, preservação e salvaguarda. Em nível internacional, a função é da Organização das Nações Unidas para Educação, Ciência e Cultura (Unesco) e, ao nível nacional, do Instituto do Patrimônio Histórico e Artístico Nacional (Iphan).

Os recursos arqueológicos são algumas das principais atrações de países como Egito, Grécia, Itália, México e Peru, entre outros, onde seus patrimônios arqueológicos são reconhecidos mundialmente e atrativos para milhares de turistas por ano. Assim, o turismo funciona como significativo meio de geração de renda para esses países (SCATAMACCHIA, 2005). Concomitantemente, diversos produtos e serviços turísticos foram criados, de modo a atender tal demanda e incentivar turistas potenciais. Roteiros temáticos são comuns em sítios arqueológicos, como o Roteiro da Bética Romana, na Espanha, e o Mayan Ruins Tours, no México. Há também espetáculos e festividades com temas históricos, como o Festival Tarraco Viva, também na Espanha.

Hotéis em prédios antigos, festivais de teatro clássico e de cinema arqueológico, e ainda comemorações sociais relacionadas a acontecimentos históricos são outros produtos e atrações turísticas criados a partir de recursos arqueológicos (TRESSERRAS, 2004).

Além de colaborar para avanços científicos, o arqueoturismo favorece o acesso a bens arqueológicos, sendo meio de divulgação de conhecimento, além de ser canal de integração entre cultura, conhecimento, preservação e desenvolvimento socioeconômico (NÓBREGA; ARAÚJO, 2015). Os vestígios arqueológicos funcionam como um diferencial competitivo devido a sua singularidade, no atual cenário massificado e repetitivo, tendo em vista o contato com um produto singular que enriquece a experiência, além de oferecer novos aprendizados. E ainda, há o fato de o aspecto de fomento sustentável para as comunidades próximas dos sítios, de modo a propiciar o reconhecimento de suas origens, reforçando o sentimento de pertencimento e de identidade (ABADIA; RAMBELLI, 2013).

Ainda que sítios monumentais sejam os atrativos de maior destaque nesse segmento, como no Egito, na Grécia e na Itália, sítios arqueológicos de outros tipos também são capazes de atrair olhares. É o caso de sítios de acampamentos, funerários, cerâmicos e, notadamente, os que apresentam arte rupestre (FIGUEIREDO; PEREIRA, 2007), tais como esculturas, petróglifos e pictóglifos². Entre alguns exemplos estão: o Parque Nacional Serra da Capivara e Parque Nacional Sete Cidades, no Brasil, e os sítios Altamira, na Espanha, o Vale do Vézère, na França, com destaque para a caverna de Lascaux.

Nesse contexto, o turismo torna-se veículo de divulgação de pesquisas arqueológicas e, consequentemente, disseminador da relevância da conservação dos espaços protegidos:

\footnotetext{
1 Patrimônio Cultural, segundo a Constituição Federal, no Art. 216, é constituído pelos bens de natureza material e imaterial, tomados individualmente ou em conjunto, portadores de referência à identidade, à ação, à memória dos diferentes grupos formadores da sociedade brasileira. Fonte: Brasil. (1988). Artigo 216 da Constituição da República Federativa do Brasil. Disponível em: 〈http://www. planalto.gov.br/ccivil_03/constituicao/constituicao.htm>. Acesso em: 01 nov. 2014.

2 Enquanto petróglifos são gravuras em rochas, os pictóglifos são pinturas nestas (PEREIRA, 2012).
} 
O turismo entendido enquanto atividade de lazer [...], capaz de atribuir função útil ao espaço e respectivos recursos ambientais (naturais e culturais) que lhe são integrantes, surge para a arqueologia como instrumento alternativo, capaz de promover com maior eficácia as ações de divulgação e difusão do conhecimento arqueológico junto ao grande público (WIDMER, 2009, p. 69).

O autor citado acima ainda destaca que, para uso eficaz pelo turismo, o processo de interpretação deve ser realizado de forma que proporcione a informação e a conscientização sobre a importância do atrativo, induzindo posturas de respeito e proteção. Norteado por tais diretrizes, o turismo pode ser agente colaborador com a integridade do patrimônio, de forma que as gerações futuras também o conheçam e tenham a consciência de preservá-lo.

El patrimonio arqueológico debe ser protegido no sólo porque es herencia que una vez destruido es irrecuperable (asociado a investigación, cultura, educación, sentido de pertenencia etc) sino porque también es una oportunidad para el progreso de la sociedad actual gracias, entre otras cosas, al turismo cultural (KULEMEYER, 2003, s/p).

Quando não há essa proteção, a tendência é acontecer como na caverna de Lascaux, no Vale do Vézère, na França, que foi vítima do turismo desordenado e sem planejamento. Famosa pela beleza e riqueza de detalhes de sua arte rupestre, a caverna recebeu, em meados do século passado, um expressivo número de turistas. Como consequência, o solo sofreu desgastes e o acúmulo de gás carbônico exalado propiciou a proliferação de bactérias que impactaram as pinturas. O espaço foi fechado à visitação, sendo permitido apenas o acesso a algumas equipes de pesquisadores. Como alternativa para o turismo, foi construída Lascaux II, uma réplica da caverna com a reprodução de parte das gravuras (MADU, 2003).

O Brasil, ocupando o $17^{\circ}$ lugar no ranking de destinos do turismo arqueológico (JORDI, 2009), mostra estar distante de participar ativamente dessa competição do mercado. Mas isso não quer dizer que o Brasil não dispõe de recursos arqueológicos, pois conta com significativos sítios, tendo grande potencial para o desenvolvimento desse segmento (NÓBREGA; ARAÚJO, 2015). Na relação de bens arqueológicos na lista de bens culturais sob proteção do Iphan, encontram-se: 11 sítios arqueológicos tombados, seis coleções arqueológicas tombadas localizadas em museus e mais de 24 mil sítios arqueológicos cadastrados (IPHAN, 2018; PORTAL BRASIL, 2017).

A realidade, no entanto, é que, conforme afirmam Abadia e Rambelli (2013), o País está em um processo anterior à promoção e à comercialização turística de destinos, produtos e serviços relacionados especificamente ao arqueoturismo. A maioria dos recursos arqueológicos brasileiros ainda encontrase nada ou pouco explorada enquanto produto turístico, que demandam planejamento específico para atender ao público (infraestrutura e serviços de apoio) sem danificá-los.

Entre os locais no Brasil onde há recursos arqueológicos para desenvolver o turismo (incluindo o pedagógico), citam-se o Parque Nacional da Serra da Capivara no Piauí, as Itacoatiaras do Ingá na Paraíba, e o Engenho dos Erasmos (localizado em Santos/SP, datado do século XVI). Porém, mesmo os que apresentam alguns resultados positivos da prática turística, o uso desses sítios deixa a desejar quando se contempla as possibilidades de ações, como também seu próprio valor. (ABADIA; RAMBELLI, 2013).

Ainda assim, percebe-se a conscientização e iniciativa de órgãos para a definição, o estudo e a legislação de assuntos relacionados à arqueologia brasileira. Levando em conta a fragilidade dos sítios arqueológicos, há proteção por uma legislação específica: a Lei n 3.924/61, através do Instituto do Patrimônio Histórico e Artístico Nacional, definindo e caracterizando sítios arqueológicos como: 
Jazidas de qualquer natureza, origem ou finalidade, que representem testemunhos da cultura dos paleoameríndios; os sítios nos quais se encontram vestígios positivos de ocupação pelos paleomeríndios; os sítios identificados como cemitérios, sepulturas ou locais de pouso prolongado ou de aldeamento "estações" e "cerâmicos"; e as inscrições rupestres ou locais e outros vestígios de atividade de paleoameríndios (IPHAN, 2014, p. 1).

Entendendo a relevância e a grande suscetibilidade a impactos naturais e antrópicos, o desenvolvimento da atividade turística nesses ambientes deve ser precedido de diagnósticos arqueológicos e planos de manejo, assim como determina a Portaria 230/2002 do Iphan. A experiência deve associar lazer, cultura e consciência a partir do processo de interpretação do patrimônio, ferramenta latente à atividade, visto que a partir de um projeto educativo e informativo bem-sucedido, criará e fortalecerá vínculos entre população e patrimônio.

Apesar dessa consciência demonstrada por meio de leis, portarias, documentos e dos inúmeros sítios arqueológicos catalogados, no Brasil há poucos sítios estruturados para o turismo como o Parque Nacional Serra da Capivara, referência em turismo arqueológico no País. Em 2013, esse Parque recebeu 19.998 visitantes, segundo informações do Instituto Chico Mendes de Conservação da Biodiversidade $\left(\right.$ ICMBio $^{3}$.

Localizado no estado do Piauí, a $530 \mathrm{~km}$ da capital, o Parque integra a lista de patrimônio da humanidade da Unesco. Possui vasto patrimônio natural e cultural e é gerido pelo ICMBio, com coparticipação da Fundação Museu do Homem Americano (Fumdham). Segundo os sites do ICMBio e da Fumdham, estão cadastrados mais de 1.000 sítios arqueológicos, das representações mais variadas: arte rupestre, acampamentos, sítios funerários, cerâmicos, arqueopaleontológicos. Desse total, 173 são estruturados para o turismo, 16 deles com acessibilidade para portadores de necessidades especiais ou mobilidade reduzida. Com boa infraestrutura turística, aproveitam-se eficazmente atrativos como cânions, trilhas, fauna, flora, cavernas e os elementos mais procurados: a arte rupestre.

Além do turismo, também são desenvolvidas inúmeras atividades científicas e trabalhos com a comunidade local, a exemplo da "Cerâmica Serra da Capivara" ${ }^{4}$, produzida pela comunidade inspirada nos trabalhos cerâmicos das populações passadas e reproduzindo as pinturas rupestres (ICMBio, 2014). Esse caso é exemplo para outros sítios arqueológicos de interesse turístico, podendo concorrer para uma valorização da localidade no qual se encontra.

Outro sítio que se encontra na relação de bens arqueológicos do Iphan é o Sítio Arqueológico Itacoatiaras de Ingá, na Paraíba. Diferentemente da Serra da Capivara, o local não tem sido aproveitado pelo turismo, além de ter passado por sérios problemas de preservação, sendo, por isso, foco dessa investigação.

\section{Sítio Arqueológico Itacoatiaras do Ingá}

O Sítio Arqueológico Itacoatiaras do Ingá situa-se no município de Ingá, no agreste paraibano, distando 98 km de João Pessoa, capital do estado, e $37 \mathrm{~km}$ de Campina Grande, segunda maior cidade paraibana. Segundo o Instituto Brasileiro de Geografia e Estatística - IBGE (2010), o município apresenta IDH de 0,592 e sua população é de 18.180 habitantes, distribuída em uma área de $287,991 \mathrm{~km}^{2}$; seus biomas são a Caatinga e a Mata Atlântica.

\footnotetext{
3 As informações aqui referenciadas tiveram como fonte o atual (2014) gestor do ICMBio - Serra da Capivara, através de contato via email.

4 Disponível em: http://www.turismo.pi.gov.br/pt-br/galeria/polo-das-origens. Acesso em: 27 maio 2014.
} 
No município de Ingá, uma de suas potencialidades para o turismo é a Serra Velha (Figura 1), um conjunto montanhoso, cujas condições geográficas favorecem a realização de esportes como rapel e escalada, ou a prática de ecoturismo, por meio de trilhas interpretativas. Há ainda a comunidade Quilombola Pedra d’Água (Figura 2), próxima ao distrito de Pontina, onde é possível realizar trabalhos de conscientização e valorização cultural da população local, podendo ser uma atrativa oferta cultural.

O Sítio Arqueológico, especificamente, localiza-se na Fazenda Pedra Lavrada, zona rural, distando aproximadamente $3 \mathrm{~km}$ da sede municipal. Possui uma área de 1,70 ha e é cortado pelo Rio Ingá, que apresenta ao longo de seu leito um extenso e irregular conjunto de rochedos lapidados pela correnteza das águas, os quais conferem uma beleza singular ao local (Figura 3). O Rio Ingá outrora servia como fonte de lazer para a população e turistas por meio de banhos, pescarias e realização de piqueniques em seu entorno. Porém, devido à poluição e conduta inapropriada de alguns frequentadores, essas atividades tiveram que ser suspensas, perdendo a cidade essa importante opção de entretenimento (ALMEIDA, 2009).

A fazenda abriga um rudimentar museu de história natural (Figura 4). E em seu acervo coabitam, sem as devidas informações, réplicas e originais de fósseis de animais pré-históricos, encontrados em sítios paleontológicos da região; instrumentos usados por paleoíndios; painéis ilustrativos e uma moldagem da Pedra do Ingá (ALMEIDA, 2009).

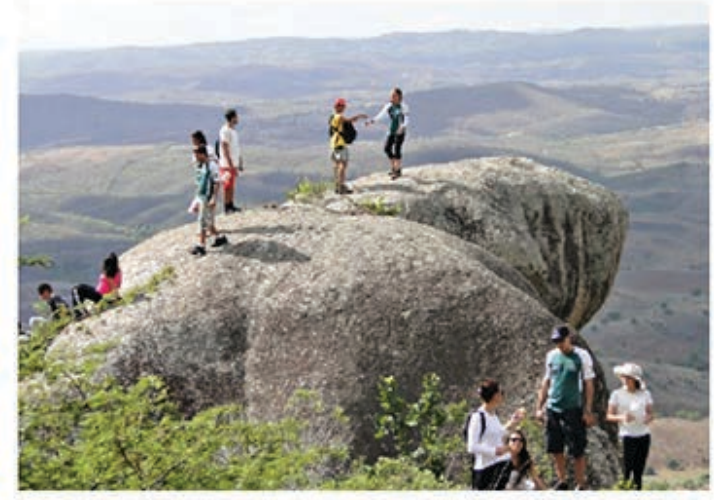

Figura 1 - Serra Velha/PB

Fonte: Blog Vavá da Luz (2014).

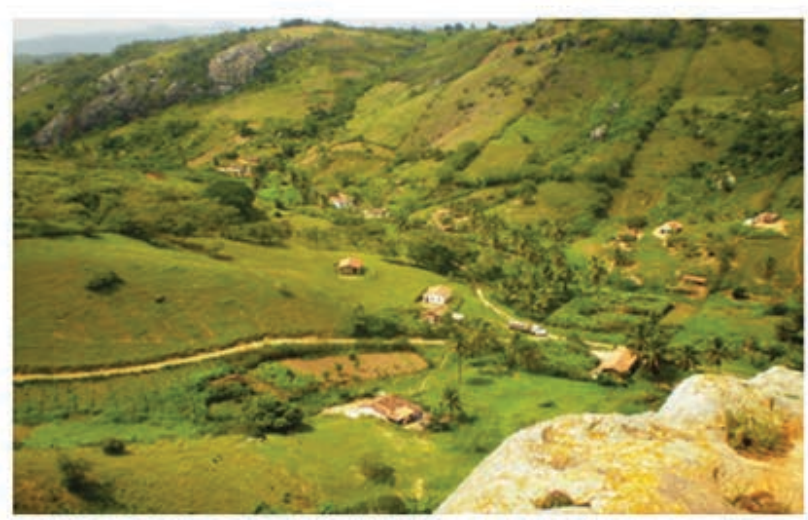

Figura 2 - Vista do Quilombola Pedra d’Água

Fonte: Andrade (2010).

No Sítio Arqueológico das Itacoatiaras do Ingá, encontra-se a Pedra do Ingá ou Itacoatiras do Ingá (Figura 5), principal atrativo turístico, que em Tupi significa pedra riscada ou pedra desenhada ${ }^{5}$. Tratase de um monumento formado por rocha granítica, onde há inscrições rupestres em baixo relevo. A Pedra constitui referência internacional de arqueologia (IPHAN, 2005), sendo o primeiro Monumento Arqueológico tombado pelo Iphan, registrado sob o número 234, no Livro Histórico do mesmo órgão, em maio de 1944.

5 Segundo informações passadas por guias de turismo do local em pesquisa de campo realizada em o8 de junho de 2014 . 

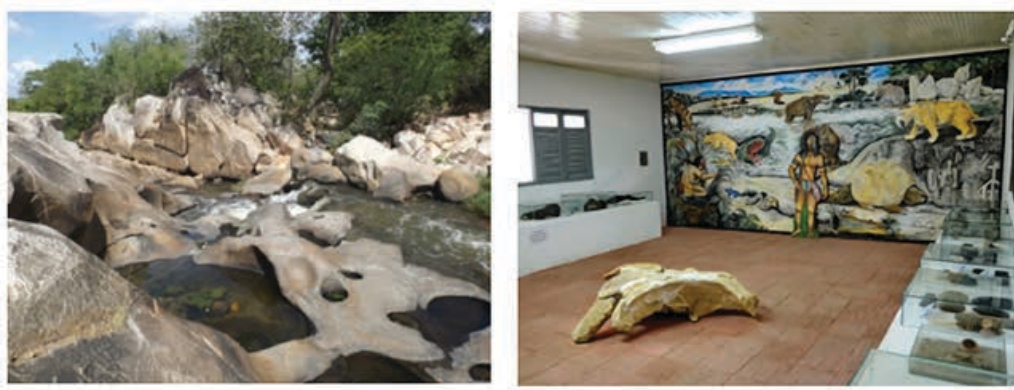

Figura 3 - Rio Ingá

\section{Figura 4 - Museu de História Natural}

Fonte: Falcão e Kiyotani (2014).

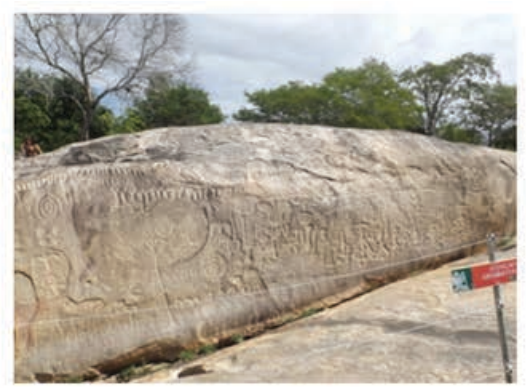

Figura 5 - Pedra do Ingá

Sobre as inscrições pairam as mais variadas versões acerca de seus autores, chegando-se até a cogitar serem realização de extraterrestres ou de fenícios, seja no imaginário popular, seja na afirmação de precursores sobre os estudos arqueológicos, como Ludwig Schwennhagen, defensor da teoria dos fenícios e autor do livro Fenícios no Brasil: antiga história do Brasil de 1.100 A.C a 1.500 D.C (BRITO, 1993).

A versão sobre extraterrestres é aventada, entre outros, por Brito (1993, p. 57): "poderíamos usar as teorias científicas para supor a presença de enviados de outro mundo galáctico, desembarcando diante da Pedra de Ingá, registrando sua passagem através de escritos". Ainda em sua investida por uma interpretação esotérica, o autor realiza complicadas operações matemáticas, cujos resultados apresentam a possibilidade de estar ali representado um calendário lunar, e também visualiza nas inscrições pontos que possivelmente representariam a constelação Órion.

Clerot (1969) enxergou nas inscrições a estilização de animais, frutas e figuras fálicas indicando a fixação de uma sequência de ideias, ou os primórdios de uma arte escultórica. De acordo com Brito (2008), pesquisador da Sociedade Paraibana de Arqueologia, tais inscrições são provenientes de comunidades indígenas pré-históricas e insculpidas com apurada técnica, apresentando fino acabamento e polimento (BRITO, 2008). Tal visão é endossada pela ciência contemporânea.

A arqueologia, entretanto, indica que as gravuras foram executadas por grupos humanos que habitaram a região antes da chegada do europeu colonizador, e que, como obras de arte expostas ao tempo, se encontram em processo de degradação (IPHAN, 2013).

Embora as muitas visões entre autores e estudiosos, verifica-se que o sítio sofreu dificuldades de preservação. Já em meados do século passado, Clerot (1969) denunciava um fato que acarretou várias perdas para o sítio arqueológico do Ingá e que, por pouco, não subtraiu do patrimônio arqueológico brasileiro as Itacoatiaras do Ingá, mesmo que já sendo tombado pelo Iphan à época:

Até bem pouco tempo o conjunto da "Pedra Lavrada" era maior [...]: Em dias de 1953 estivemos no local, surpreendendo uma turma de operários cavouqueiros, destruindo o pedregal; os blocos de cercadura nas duas margens do rio estavam sendo reduzidos a rachões e paralelepípedos para pavimentação de ruas da Capital (CLEROT, 1969, p. 126).

A isso, acrescentam-se dificuldades do âmbito natural, uma vez que, nos períodos de cheia, o nível das águas do rio se eleva, podendo encobrir momentaneamente as Itacoatiaras, de modo a gerar preocupação devido à possibilidade da correnteza, que, com o material arrastado durante as enxurradas, pode causar desgastes ao monumento. 
Tendo em vista constatar o atual contexto desse sítio, após estudos de diversos profissionais, e após a dificuldade de preservação, coletaram-se dados específicos desse sítio arqueológico. Assim, poder-se-á identificar medidas possíveis e viáveis para sua integração à atividade turística.

\title{
Dados da pesquisa
}

Em pesquisa realizada na biblioteca do Iphan, com ampla documentação, sendo grande parte propostas das décadas de 1980 e 1990, foi possível analisar alguns projetos e ações, embora sua maioria tenha permanecido em forma de projetos e intenções. Em justificativa de proposta de planejamento de revitalização do sítio, o Instituto afirma que:

\begin{abstract}
A falta de um projeto integral que alie a preservação e a utilização racional daquela ocorrência arqueológica fez com que pequenas ações isoladas, a exemplo da implantação de guaritas e cercas de proteção e melhorias das instalações físicas dos equipamentos existentes fossem realizadas, mas sempre dissociadas de um plano geral (IPHAN/PB, 2005, $\mathrm{s} / \mathrm{p})$.
\end{abstract}

Há de se destacar que, mesmo o tombamento desse sítio arqueológico tendo sido realizado em 1944, mais de 60 anos antes do documento acima citado, ainda era inexistente um projeto visando o uso apropriado desse recurso, objetivando não somente protegê-lo como preservá-lo.

Em 2005, o Governo do Estado, por meio da Superintendência de Obras do Plano de Desenvolvimento, concluiu um projeto denominado "Parque Arqueológico Itacoatiaras do Ingá/PB - Projeto do Centro de Referência Nacional de Arqueologia” (IPHAN, 2005b). O projeto, entretanto, encontrou forte resistência dos arqueólogos do Iphan por entenderem ser necessária a prévia realização de um Diagnóstico Arqueológico e Plano de Manejo, tal como prevê o referido órgão através da Portaria 230/2002. Essa Portaria exige que a realização de pesquisas arqueológicas tenha, em todas as fases, licenciamento ambiental para empreendimentos potencialmente capazes de afetar o patrimônio arqueológico (PEREIRA, 2012).

Uma primeira vistoria sobre projeto foi solicitada pelo Iphan/PB e realizada em junho de 2005, sendo emitido o seguinte parecer: "Consideramos temerária qualquer intervenção no sítio, sem a sua consideração e sem a elaboração de estratégias mitigadoras. É necessário, então, identificar os impactos para poder otimizar os benefícios e por sua vez mitigar os danos" (IPHAN, 2005c, s/p). No parecer, são elencados alguns fatos negligenciados no projeto de Revitalização do Sítio Arqueológico das Itacoatiaras de Ingá e que careceriam de intervenção urgente, como a exposição do monumento a atos de vandalismo; intemperismo físico e químico, causadores de escamação e desplacamento e o uso da área do solo no entorno do sítio.

Quase dez anos depois, em 2013, foi realizado por uma equipe mista de profissionais da Universidade Federal do Piauí o projeto "Estudos Arqueológicos, Conservação e Socialização do Sítio Itacoatiaras do Ingá". Tendo como foco a pesquisa científica, o projeto foi classificado pela equipe responsável como a "primeira abordagem arqueológica da Pedra do Ingá, dentro dos preceitos científico-metodológicos legais" (IPHAN, 2013, p. 30).

A equipe observou fatores químicos, físicos, biológicos e antrópicos que comprometem a integridade da rocha, sendo os principais: desplacamentos, biodepósitos, exposição ao sol e à chuva, cheias do rio que causam submersão das gravuras, vegetação rupestre envolvendo a pedra, restos de resina outrora usada na moldagem das gravuras, fluxo turístico desordenado e a presença de animais domésticos na área (IPHAN, 2013). 
Foram realizadas sondagens em áreas onde se pretende ampliar os limites do sítio a fim de transformálo em Parque Estadual das Itacoatiaras do Ingá. Dessas áreas, a ocorrência arqueológica denominada sítio oficina Cansação foi a que apresentou descobertas mais significativas, sendo atribuída ao local a função de oficina paleolítica, devido à diversidade dos materiais e formato dos vestígios encontrados. As evidências encontradas, além de representarem forte interesse para pesquisas, podem também contribuir para a ampliação de atrativos para o turismo. A equipe deduziu que a Pedra do Ingá foi "um local sagrado, ocupado reiteradamente por vários grupos humanos" (IPHAN, 2013, p. 27). Durante as sondagens, foram coletados materiais arqueológicos das categorias lítico, louça, carvão e metal, com datações de 80 a 610 anos.

Uma atividade realizada à época foi o levantamento fotográfico em 3D por meio de uma varredura a laser, executado por equipe da Universidade Federal de Pernambuco. Essa tarefa visou realizar a documentação imagética do sítio e seu entorno e o levantamento imagético plano a plano do painel principal. Tal procedimento será de significativa relevância à atividade turística, caso um dia seja possível um painel digital dentro do museu.

Compreende-se que os documentos gerados na busca de viabilizar a implantação do Parque Estadual não têm contribuído incisivamente para esse fim. Parece haver uma inaptidão de cumprir as exigências legais necessárias ao lidar com o patrimônio arqueológico. Os projetos apresentam-se falhos quanto à transdisciplinaridade, visto que ou mostram-se basicamente "arquitetônicos" (IPHAN 2005b), ou têm foco notadamente científico, faltando um projeto que contemple ambos os aspectos, sem falar de um relacionado ao turismo em si. E ainda, sabe-se que esse tipo de estudo requer continuidade, pois fatores como longo espaço temporal, diferentes usos do solo e proximidade geográfica do rio, que periodicamente revolve todo o material de seu entorno, dificultam a detecção de evidências das antigas populações.

Quanto à estrutura e condições atuais de visitação e uso turístico das Itacoatiaras do Ingá, abordam-se vários aspectos, como as formas de acesso, a infraestrutura e os serviços oferecidos. Por meio de transporte intermunicipal (ônibus), o acesso ao sítio tem duas vias principais: duas saídas diárias de João Pessoa e três partindo de Campina Grande, também diariamente. O acesso por veículo particular é feito pela BR-230.

A sinalização para o Sítio Arqueológico das Itacoatiaras dentro da cidade é eficiente, tendo inclusive sinalização turística. Porém, o portal turístico inacabado (Figura 6) não transmite uma boa primeira impressão. A cidade é relativamente arborizada e, aparentemente, bem policiada. Em visita realizada em junho de 2014, a Igreja Matriz e a praça estavam bem conservadas e decoradas para os festejos juninos, enfatizando os tons da bandeira brasileira, em alusão à Copa. No entanto, verificaram-se que apenas nessa área foram localizados equipamentos como lixeiras e rampas de acessibilidade, ficando o restante da cidade carente de tais serviços, inclusive o Sítio Arqueológico.

O comércio local é modesto, condizente com uma pequena cidade interiorana, não estando preparado para atender a uma grande demanda de turistas. Como meio de hospedagem, há apenas uma pousada, de instalações precárias, embora, segundo informações do secretário de Turismo, dois hotéis estejam sendo construídos ${ }^{6}$.

Um pequeno percurso em rodovia asfaltada, de aproximadamente $3 \mathrm{~km}$, com paisagem tipicamente rural, poucas edificações e natureza onipresente, liga o centro da cidade às Itacoatiaras do Ingá. $\mathrm{O}$ estacionamento fica na área externa e não é pavimentado. Há um totem sinalizador e, como também

6 Em entrevista realizada em 08 de junho de 2014. 
foram encontrados vestígios paleontológicos na área, foi confeccionada a escultura de um gliptodonte, espécie de preguiça da megafauna, que viveu naquela região no período pleistoceno ${ }^{7}$ (Figuras 7 e 8).

Chegando ao sítio, há uma guarita vazia, onde as informações pertinentes aos horários, conduta, órgãos responsáveis e implicações legais estão afixadas por meio de cartazes e pinturas. Mesmo sendo um atrativo que recebe turistas estrangeiros, não há tradução das informações para inglês ou espanhol. Não é cobrada nenhuma taxa para entrada, ficando a critério do visitante fazer ou não uma doação, que é sugerida por meio de um dos avisos.

A presença de apenas dois guias acarreta prejuízos à visitação. Não havendo pessoal para fazer o revezamento, no horário de almoço o museu fica fechado e não é possível realizar visitas guiadas. Os visitantes, portanto, não têm acesso a informações sobre o monumento, já que não há placas informativas ou qualquer material que favoreça visitas autoguiadas.

Um prédio em estilo de fazenda - uma ampla casa rodeada por alpendres - abriga as instalações sanitárias, um balcão de informações, o pequeno Museu de História Natural e a Secretaria de Turismo. A partir desse prédio, segue-se por uma breve rampa que termina abruptamente e, continuando, um trecho acidentado, o qual dá acesso às Itacoatiaras, tornando o monumento inacessível a cadeirantes ou pessoas com mobilidade reduzida.
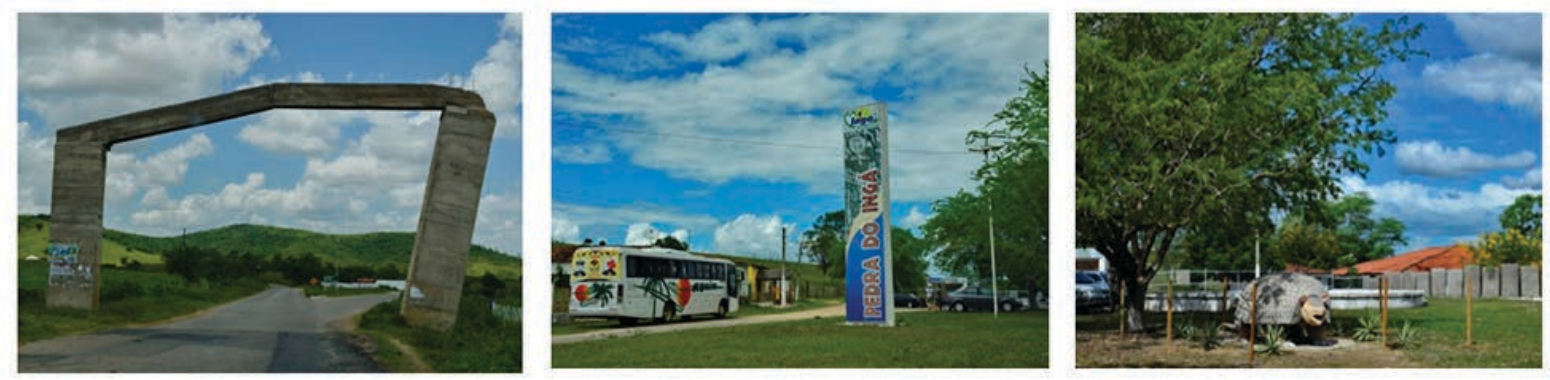

Figura 6 - Portal de entrada do Sítio Figura 7 - Totem na entrada do Sítio Figura 8 - Escultura de um gliptodonte

Fonte: Roberto Guedes Pereira (2014).

Os visitantes são recepcionados por um guia, que os conduz às Itacoatiaras e apresenta uma breve palestra sobre a história do sítio, os achados arqueológicos, as diversas teorias levantadas a respeito dos autores e enigmas das inscrições, e a suscetibilidade do monumento aos desgastes naturais e antrópicos. Enfim, discorre sobre sua importância tanto para o município quanto para o cenário nacional e mundial. Os guias também distribuem folders que apontam outros pontos de interesse turístico do município.

Terminada a explanação do guia, os visitantes encaminham-se para o museu e tomam conhecimento do pequeno acervo, composto basicamente de réplicas, alguns achados arqueológicos e paleontológicos, além de painéis ilustrativos. Ao lado da entrada do museu encontra-se uma espécie de cofre para receber as doações, que são a única fonte de renda para os serviços ali realizados, visto que, de acordo com o secretário de Turismo, a participação financeira da prefeitura cobre apenas despesas com o pagamento do pessoal.

70 pleistoceno corresponde ao intervalo entre 1,8 milhão e 11.500 anos atrás [...] Pássaros e mamíferos gigantes, como mamutes e búfalos, caracterizam essa época. Fonte: Bernardo, D. V. (2012). Homem da América conviveu com mamíferos gigantes. Revista Veja. Disponível em: 〈http://veja.abril.com.br/noticia/ciencia/homem-da-america-conviveu-com-mamiferos-gigantes〉. Acesso em: 30 jul. 2014 . 
Em entrevista concedida em junho de 2014, o então secretário de Turismo Municipal, Valtermário Góis da Luz, mostrou-se ciente do potencial turístico de Ingá, com capacidade para desenvolver diversos segmentos turísticos, como rural, cultural e pedagógico, o mais praticado, segundo ele. Porém, lamenta a falta de recursos e incentivos e até mesmo de políticas públicas, inclusive do legislativo municipal, para impulsionar o turismo na região.

Suas principais queixas são relacionadas à falta de infraestrutura: "Divulgamos as Itacoatiaras no céu, no mar e na terra e não temos como receber o povo". O déficit está presente não somente no sítio, mas também nos serviços de alimentação, hospedagem, transporte e lazer. Falta principalmente qualidade, pois os poucos estabelecimentos existentes não dispõem de pessoal capacitado.

Do ponto de vista do secretário, empreender na região chega a ser uma questão de coragem. Ele se empolga com os pioneiros, pois vê nesses elementos incentivos para outros comerciantes que ali queiram se instalar. Como medidas dinamizadoras, investimentos estão sendo realizados, projetos alternativos, como a associação de aquicultores para criação de peixes, que tanto pode servir como matéria-prima no cardápio dos restaurantes quanto para incentivar o turismo rural, mas, principalmente para impulsionar a economia local.

O secretário apresentou um projeto para incluir no currículo escolar municipal conteúdo referente às Itacoatiaras e à história de Ingá. Para justificá-lo, utiliza como exemplo sua própria formação, a qual, mesmo sendo natural daquela cidade, cresceu sem a consciência da importância das Itacoatiaras, despertando para sua magnitude por meio da visão de turistas estrangeiros que vieram visitá-las. O secretário pensa no projeto como um caminho "para que as crianças possam crescer admirando, protegendo e divulgando aquelas Itacoatiaras".

O projeto ainda não foi posto em prática por uma série de exigências necessárias para que se proceda com a alteração de um currículo escolar. No entanto, estão sendo organizadas visitas periódicas da rede de ensino, a fim de fortalecer a relação de pertencimento, apostando assim na formação a médio e longo prazo. Além desta, há iniciativas como a formação, não oficial, dos "guias mirins", com alunos do programa federal Pró-jovem, que participam de um curso no qual guias da prefeitura dividem seus conhecimentos com os alunos ${ }^{8}$.

Mais uma de suas propostas é a reativação da malha ferroviária que liga o município à Itabaiana, incorporando o conceito de trens turísticos ${ }^{9}$. Porém, não há nenhuma previsão de ser posta em prática, estando ainda na fase de contatos com as autoridades competentes.

O secretário aposta em uma alavancada do turismo quando finalmente for implantado o Parque Estadual das Itacoatiaras do Ingá, projeto iniciado ainda em 2005, mas que vem se deparando com várias barreiras, seja nas exigências dos estudos prévios, seja na morosidade da Justiça quanto à conclusão dos processos de desapropriações. Mesmo com todas as adversidades, ele se sente otimista em relação ao turismo e usa como exemplo a aproximação da iniciativa privada com a construção de dois hotéis no município e o volume de visitas no Sítio do Ingá que, segundo suas informações, é em torno de 3.000 pessoas ao mês.

\footnotetext{
8 Ainda no ano de 2014.
}

9 Os serviços de trens turísticos e culturais caracterizam-se pelo transporte não regular de passageiros, com o objetivo de agregar valor aos destinos turísticos, contribuindo para a preservação da memória ferroviária, configurando-se em atrativos culturais e produtos turísticos das cidades, auxiliando-as na diversificação da oferta. Fonte: Ministério do Turismo [MTur]. (2010). Turismo Cultural: orientações básicas. 3. ed. Disponível em: 〈http://www.turismo.gov.br/export/sites/default/turismo/o_ministerio/publicacoes/ downloads_publicacoes/Turismo_Cultural_Versxo_Final_IMPRESSxO_.pdf〉. Acesso em: 05 nov. 2014. 


\section{Análise dos Dados}

Ao analisar as informações obtidas a partir desta pesquisa, fica constatado que a desinformação e o despreparo vêm atuando como um gargalo para o desenvolvimento turístico de qualidade na região, além da insuficiente infraestrutura.

Os horários de acesso ao município por transporte público não são favoráveis à prática turística, principalmente os que partem da capital, dificultando a visitação por não haver saída matutina, somandose o fato de Ingá não possuir boa estrutura de estadia. Por transporte privado, as dificuldades também se apresentam, não pela qualidade da rodovia, mas pela falta de sinalização. Ao longo da BR-230 só existem placas indicativas nas proximidades da entrada para o município. Assim, durante todo o percurso não se tem a noção de distanciamento, nem confirmação de estar seguindo o caminho correto.

Por mais que a cidade seja arborizada e, aparentemente, segura, seria viável um trabalho de urbanização ou até mesmo um concurso entre os moradores que selecionasse a "melhor fachada" ou o "melhor jardim", a fim de tornar a paisagem mais atrativa e acolhedora.

Percebe-se também a falta de equipamentos de lazer e entretenimento capazes de atrair a atenção do visitante, que se desloca diretamente para as Itacoatiaras. Diminui-se, portanto, as oportunidades de interação e convivência entre turistas e a comunidade, o que acarreta pouca atratividade para alongar a permanência turística.

No que diz respeito ao próprio sítio arqueológico, vê-se falha no tocante à segurança, pois não há guardas e, mesmo que seja uma região pacata, seria conveniente o patrulhamento, tanto para a integridade dos turistas quanto para a do próprio monumento. Estar-se-ia, assim, protegendo-o da ação de possíveis vândalos, que em tempos passados já empreenderam pichações e depredações no local.

A estrutura física também se apresenta como necessitada de cuidados, como é o caso do prédio em estilo de fazenda, cujo forro do teto está caindo. A rampa que dá acesso às Itacoatiaras também precisa notadamente de ajustes, uma vez que as tornam inacessíveis a pessoas com mobilidade reduzida. Para torná-lo acessível a esse público, é fundamental a construção de um caminho possível de transitar com segurança.

Reconhece-se, portanto, que a localidade apresenta grande fragilidade, por tratar-se de um sítio arqueológico, traduzindo-se em um ambiente com restrições e implicações, inclusive legais, para o desenvolvimento de qualquer atividade.

Ainda que sejam distribuídas informações sobre outros pontos turísticos aos visitantes, nota-se que não há programação regular ou agência de receptivo para atendê-los, muito menos infraestrutura turística.

Percebe-se ainda que há uma disparidade entre ciência e gestão. Com base em documentação do Iphan/ $\mathrm{PB}$, verifica-se que a falta de conhecimento técnico e científico proporciona um atropelo de interesses. $\mathrm{O}$ Governo do Estado da Paraíba apresentou um projeto relativamente grandioso de infraestrutura, mas sem obedecer às exigências legais, fato que poderia comprometer fortemente o patrimônio arqueológico, inclusive possíveis sítios ainda não descobertos. Impasses jurídicos quanto às questões de desapropriações e indenizações também colaboraram para a inviabilização de uma estruturação adequada, capaz de contemplar questões de desenvolvimento econômico, além da preservação e valorização do patrimônio arqueológico. 
A disponibilização de trabalhos já realizados sobre as Itacoatiaras, acadêmicos ou não, enriqueceria a visitação do sítio, sendo uma ferramenta de reforço para educação patrimonial, uma vez que quanto maior o volume de informações, mais forte torna-se o envolvimento dos atores. Mídias, como registros videográficos, apresentam-se como um diferencial capaz de dinamizar a experiência. Essas pesquisas podem fornecer informações e soluções para a implantação de uma visitação consciente e otimizada ao patrimônio, sem ônus extras ao município ou estado, visto que já são realizadas por instituições públicas ou privadas.

Um dos problemas observados durante esta pesquisa foi a baixa diversificação da oferta para o turismo. A atividade no município de Ingá está praticamente limitada à visitação do sítio arqueológico, que, entre as explicações de guias nas Itacoatiaras e a visita ao museu, dura aproximadamente uma hora. A maioria dos turistas sequer almoça nos restaurantes da cidade. Muitos partem para cidades com melhor infraestrutura, como Campina Grande.

Na prática turística em Ingá, o contato entre os visitantes e a população é muito reduzido, fato que além de excluir a comunidade do processo, acarreta perdas para o turista, pois deixa de vivenciar aproximações culturais. A formatação de produtos capazes de contemplar esse tipo de relação provavelmente contribuiria significativamente para o enriquecimento da atividade, por exemplo, se existissem dentro ou próximo ao museu lojas de artesanato com temas ligados às Itacoatiaras - o levantamento do patrimônio material e imaterial das Itacoatiaras realizado pelo Iphan (2013) poderia ser usado como base para o desenvolvimento desse artesanato.

Algumas medidas vêm sendo executadas na tentativa de melhorar a oferta e conservação do sítio, porém, a falta de entrosamento entre os poderes é prejudicial para todos, na medida em que falta o diálogo e os problemas, que já não são poucos, prolongam-se indefinidamente até que surja uma solução. Em vez de medir forças, os órgãos responsáveis pela administração e gestão do Patrimônio deveriam estar preocupados em uni-las, a fim de estabelecer uma administração efetiva e integrada, capaz de oferecer melhores condições de visitação, bem como a conservação do sítio.

\section{Considerações finais}

$\mathrm{O}$ arqueoturismo, praticado em diversos países, tem se tornado um segmento interessado em atrair mais visitantes. O Brasil, no entanto, ainda passa por dificuldades na implementação e execução desse turismo, ainda que tenha alguns casos pontuais positivos. Um dos potenciais arqueológicos brasileiros, as Itacoatiaras do Ingá, foi o objeto de estudo desta pesquisa, em uma busca pelo reconhecimento das condições de visitação turística ao local.

Analisando a situação do turismo no município de Ingá é inevitável a constatação de que há um subaproveitamento de seu potencial. Particularmente, o Sítio carrega um atrativo arqueológico de grande importância internacional, sendo um exemplar de destaque nesse tipo de ocorrência, pois certamente seus autores empregaram uma tecnologia muito avançada para a época, permitindo-o atravessar tantas gerações, mesmo em face às provas impostas pela natureza e pelo próprio ser humano.

Resta à sociedade contemporânea preservar esse legado, utilizando-se das novas tecnologias, técnicas e métodos de planejamento. As Itacoatiaras, que chamam atenção de pessoas do mundo inteiro, muitas vezes passam despercebidas para muitos de seus herdeiros diretos, os paraibanos. Surge aí uma questão 
delicada: a valorização do patrimônio, o orgulho da cultura e o pertencimento, ao reconhecer-se nos detalhes.

É necessário o investimento em obras estruturantes, como de acesso, comunicação e esgotamento sanitário. Mas, também, faz-se indispensável a valorização da cultura, da capacitação dos recursos humanos, da hospitalidade, da diversificação das opções de lazer e do incremento no atendimento, com criação de cardápios regionais. Tais elementos podem incorporar a produção interna, evidenciando o efeito multiplicador do turismo.

Contribuiria bastante para o incremento do turismo a criação de roteiros nos quais as Itacoatiaras fossem a atração principal, mas que contemplassem diversos outros produtos, estrategicamente planejados para aumentar o interesse e permanência dos visitantes, além de estabelecer parcerias com outros municípios, buscando a formação de polos turísticos.

Uma opção para impulsionar o turismo arqueológico na região seria a divulgação de seus produtos arqueoturísticos durante eventos e feiras de outros segmentos, capazes de convergir um bom número de participantes que não necessariamente estariam interessados nesse tipo de prática. A realização de eventos culturais no sítio ou em seu entorno, desde que observados o tipo de evento e volume de participantes, a fim de não impactar negativamente o ambiente, também pode funcionar como estratégia de promoção.

No tocante à proteção legal, viu-se que o tombamento é instrumento primordial à salvaguarda do patrimônio, obedecendo a uma série de pré-requisitos. É a partir dele que as autoridades competentes estão amparadas para intervir em sua conservação. Porém, sem ações efetivas, esse ato administrativo tem força apenas documental. Multiplicam-se os exemplos de espaços e monumentos que, mesmo tombados, não usufruem de devida proteção. Muitas vezes, a lentidão burocrática e judicial sentencia-os à destruição, antes mesmo de qualquer intervenção.

O Sítio Arqueológico das Itacoatiaras do Ingá teve seu tombamento em maio de 1944. Decorridos setenta anos, pouco se tem notado de diferente na infraestrutura daquela ocorrência arqueológica. População e autoridades anseiam pela transição do atrativo de sítio arqueológico para Parque estadual, na esperança de um desenvolvimento sustentável.

Preservar, valorizar e difundir sua existência é função não só dos poderes públicos, como também de toda a sociedade. É necessário um engajamento coletivo de todos os setores, uma vez que este é um patrimônio nacional, com condições de contribuir tanto para a autoestima da comunidade como para a dinamização econômico-social.

\section{Referências}

ABADIA, B. F. C.; RAMBELLI, G. Arqueologia pública e turismo: possibilidades para o desenvolvimento do arqueoturismo em Laranjeiras/SE. Anais I Semana de Arqueologia. Unicamp "Arqueologia e Poder". Campinas: LAP/NEPAM, 2013. Disponível em: 〈http://www.nepam.unicamp.br/arqueologiapublica/ revista/anais/arqueologia-patrimonio-e-turismo/PDFs/arquivo4.pdf>. Acesso em: 13 fev. 2015.

ALEIXO, T. S. T. 0 arqueoturismo no domínio do património náutico e subaquático. Dissertação (Mestrado) - Escola Superior de Hotelaria e Turismo do Estoril. Estoril: 2010. Disponível em: 〈http:// comum.rcaap.pt/handle/123456789/2387〉. Acesso em: 14 abr. 2015. 
ALMEIDA, M. T. S. C. R. A pedra do Ingá: a reprodução do mito, a reprodução da fé. Dissertação (Mestrado) - Universidade Federal da Paraíba, João Pessoa, PB, Brasil, 2009. Disponível em: 〈http:// livros01.livrosgratis.com.br/cp110250.pdf〉. Acesso em: 10 abr. 2015.

ANDRADE, A. S. D. K. Luz na Comunidade Quilombola Pedra d’Água. Trabalho de Conclusão de Curso. Universidade Estadual da Paraíba, Campina Grande, PB, Brasil, 2010. Disponível em: 〈http://dspace. bc.uepb.edu.br:8080/xmlui/bitstream/handle>. Acesso em: 06 dez. 2014.

Blog do Vavá da Luz. Disponível em: 〈http://blogdovavadaluz.com/〉. Acesso em: 1 maio 2014.

BRITO, G. Viagem ao Desconhecido: os segredos da Pedra do Ingá. 2. ed. Brasília-DF, 1993.

BRITO, V. Welcome to Inga: atividade turística local e as ações públicas preservacionistas na Pedra do Ingá. Revista Virtual Alpharrabios. v. 2, n.1. 2008. Disponível em: 〈http://eduep.uepb.edu.br/ alpharrabios/v2-n1/html/WELCOME_TO_INGA.htm>. Acesso em: 27 nov. 2014.

CLEROT, L. F. R. 30 Anos na Paraíba: memórias corográficas e outras memórias. Rio de Janeiro: Editora Pongetti, 1969.

FIGUEIREDO, S. J. L.; PEREIRA, E. Turismo e Arqueologia na Amazônia Brasil: aspectos de preservação e planejamento. 2007. In: SEMINÁRIO DA ASSOCIAÇÃO NACIONAL DE PESQUISA E PÓS-GRADUAÇÃO EM TURISMO, 4. São Paulo. Anais... São Paulo: Universidade Anhembi-Morumbi. v. 1, p. 235-250. Disponivel em: 〈http://www.scielo.br/scielo.php?pid=S1981-81222009000100014...sci〉. Acesso em: 2 set. 2014 .

INSTITUTO BRASILEIRO DE GEOGRAFIA E ESTATíSTICA. População Ingá (PB). Censo 2010. Disponível em: 〈http://cidades.ibge.gov.br/xtras/temas.php?lang $=\&$ codmun $=250680 \&$ idtema $=16 \&$ searc $>h=\|$ s\%EDntese-das-informa\%E7\%F5es>. Acesso em: 06 dez. 2014.

INSTITUTO CHICO MENDES DE CONSERVAÇÃO DA BIODIVERSIDADE. Parque Nacional Serra da Capivara. 2014. Disponível: em 〈http://www.icmbio.gov.br/portal/o-que-fazemos/visitacao/ucs-abertas-avisitacao/199-parque-nacional-da-serra-da-capivara.html>. Acesso em: 06 dez. 2014.

INSTITUTO DO PATRIMÔNIO HISTÓRICO E ARTíSTICO NACIONAL. Plano de Ação, Levantamento de Demandas. (Documento disponibilizado para consulta). 2005.

INSTITUTO DO PATRIMÔNIO HISTÓRICO E ARTÍSTICO NACIONAL. Parque Arqueológico Itacoatiaras de Ingá/PB: projeto do Centro de Referência de Arqueologia. (Documento disponibilizado para consulta). 2005b.

INSTITUTO DO PATRIMÔNIO HISTÓRICO E ARTÍSTICO NACIONAL. Parecer sobre o Projeto: Parque Arqueológico Itacoatiaras do Ingá. (Documento disponibilizado para consulta). $2005 \mathrm{C}$.

INSTITUTO DO PATRIMÔNIO HISTÓRICO E ARTíSTICO NACIONAL. Sítio Pedra do Ingá: prospecção, sondagem, escavação, conservação do painel principal e socialização. (Documento disponibilizado para consulta). 2013.

INSTITUTO DO PATRIMÔNIO HISTÓRICO E ARTÍSTICO NACIONAL. Site Oficial. Disponível em: 〈http:// portal.iphan.gov.br/portal/montarPaginalnicial.do>. Acesso em: 28 fev. 2018.

INSTITUTO DO PATRIMÔNIO HISTÓRICO E ARTÍSTICO NACIONAL. Relatório de Vistoria ao Sítio Arqueológico Pedra do Ingá. (Documento disponibilizado para consulta). 2005.

JORDI, J. T. (Org.). Turismo arqueológico no Parque Nacional Serra da Capivara (Piauí-Brasil). Ministério do Turismo, Brasil. Brasília, DF, 2009. 
KULEMEYER, J. Propuesta para el desarrollo del turismo arqueológico en Argentina. Naya Notícias de Antropología y Arqueología. 2003. Disponível em: 〈http://www.naya.org.ar/turismo/articulos/ jorge_kulemeyer.htm>. Acesso em: 22 fev. 2015.

MADU, G. A. Arte Rupestre no Brasil. 2. ed. Rio de Janeiro: Joge Zahar, 2006.

MANZANATO, F. Turismo Arqueológico: diagnóstico e análise do produto arqueoturístico. Pasos Revista de Turismo e Patrimônio Cultural. v. 5, nํ⒈ 2005. Disponível em: 〈www.pasosonline.org/ Publicados/5107/PS080107.pdf>. Acesso em: 28 abr. 2015.

NÓBREGA, W. R. M.; ARAÚJO, F. Cultura, turismo e desenvolvimento: reflexões acerca do potencial arqueológico no município de Carnaúba dos Dantas (RN). Revista Brasileira de Ecoturismo. São Paulo, v. 8, n. 1, fev/abr, p. 93-114. Disponível em: 〈http://www.sbecotur.org.br/rbecotur/seer/index.php/ ecoturismo/article/viewFile/844/766 . Acesso em: 28 abr. 2015.

PEREIRA, E. A. Arte Rupestre de Monte Alegre, Pará/AM. E-book. 2012. Disponível em: 〈http://issuu. $\mathrm{com} / \mathrm{museu}$-goeldi/docs/arte_rupestre_todo >. Acesso em: 16 jun. 2014.

PORTAL BRASIL. Brasil possui mais de 24 mil sítios arqueológicos cadastrados. 2017. Disponível em: 〈http://www.brasil.gov.br/cultura/2017/o9/brasil-possui-mais-de-24-mil-sitios-arqueologicoscadastrados>. Acesso em: 28 fev. 2018.

SCATAMACCHIA, M. C. M. Turismo e Arqueologia. São Paulo: Aleph. 83 p. 2005.

TRESSERRAS, J. J. El arqueoturismo o turismo arqueológico: un paso más para la valorización del patrimonio arqueológico. Boletín GC Gestión Cultural, nำ 9. Turismo Arqueológico, 2004.

WIDMER, M. G. Turismo Arqueológico. In: PANOSSO NETTO, A.; ANSARAH, M. G. R. (Org.). Segmentação do Mercardo Turístico: estudos, pesquisa e perspectivas. Barueri, SP: Manole, 2009. 